\title{
Altered Fractionation Intensity Modulated Radiotherapy with concurrent chemotherapy in head and neck cancer : a feseability study
}

\author{
Manjula M.V. ${ }^{1}$, Y.S. Pawar ${ }^{2}$, Ashok S. ${ }^{3}$, Karthikeyan K. ${ }^{4}$, \\ ${ }^{1}$ Manjula M.V, Radiation Oncologist, ${ }^{2}$ Y.S. Pawar, Radiation Oncologist, ${ }^{3}$ Ashok S, Medical Physicist and RSO, \\ ${ }^{4}$ Karthikeyan K, Medical Physicist and RSO, Department of Radiation Oncology, Yashoda Superspecailaity Hospital, \\ Secunderbad, Telangana, India.
}

Corresponding Author: Y.S. Pawar, Department of Radiation Oncology, Yashoda Superspeciality Hospital, Secunderabad, Telangana, India. E-mail: dryspawar@gmail.com

\begin{abstract}
Purpose: To assess the loco regional response and toxicity of patients to concurrent chemo-radiation with 6 fractions/week using Intensity Modulated Radiotherapy in locally advanced head and neck cancers. (oropharynx and hypopharynx). Materials and Methods: 20 patients with Stage III and stage IV, squamous cell carcinoma of Head and neck were enrolled. Target Volume Delinetion was done in accordence with Danish Head and Neck cancer group (DAHANCA) contouring guidelines. Differential radiation dose of $70 \mathrm{~Gy}, 63 \mathrm{~Gy}$ and $56 \mathrm{~Gy}$ in 35 fractions using IMRT, delivered to GTV, CTV1 and CTV2 with weekly cisplatin with weekly assessment of response and toxicity. Results: The median age of the patients was 54 years ranging from 40 to 65 years. 14 and 6 patients had Hypopharyngeal and Oropharyngeal malignancy of squamous cell origin. $95 \%$ of patients received $70 \mathrm{~Gy}$ in 35 fractions with 4 cycles of concurrent Cisplatin. 18 patients completed treatemnt within 45 days of OTT. 16 patients had complete response and 4 had partial response. Grade I, II dermatitis was observed in $70 \%$ and $30 \%$ of patients, respectively. 5 patienst developed Grade 2 and 1 patinet developed grade 3 leucopenia. 2 patients had weight loss of more than $10 \% .85 \%$ oforopharyngeal cancers and $67 \%$ of hypopharyngeal cancers showed complete response. Nodal response was $100 \%$ complete in N1 \& N2a, $92 \%$ and $0 \%$ in N2b and N3 lesions respicyively. TNM stage group wise the complete response rates were $100 \%$ in stage III, 92\% \& $0 \%$ IVA \& IVB. Conclusion: Accelerated fractionation with IMRT and concurrent chemotherapy is a feasible in locoregionally adanced head and neck cancers with acceptable toxicities and good locoregional response rates.
\end{abstract}

Key words : Altered fractaionation, IMRT, Concurrent chemoradiation

\section{Introduction}

The incidence of squamous-cell carcinoma of the head and neck (HNSCC) is increasing, and it is the fifth most common malignant disease in the world, with more than $70 \%$ of cases occurring in the developing world (India) [1]. It is one of the ten leading causes of cancer in India, according to population based cancer registry accounting for $23 \%$ of all cancer in males and $6 \%$ in females [2]. HNSCC is a loco-regional disease confined to the primary site and its regional lymph nodes, with distant metastasis being rarely found at diagnosis. Thus loco-regional treatments like Radiotherapy (RT) \& Surgery are the primary modality of treatment. With the evolution of "Concept of organ and function preservation" RT is preferred over mutilating surgeries.

Manuscript received: $10^{\text {th }}$ November 2018

Reviewed: $20^{\text {th }}$ November 2018

Author Corrected: $30^{\text {th }}$ November 2018

Accepted for Publication: $6^{\text {th }}$ December 2018
However tumors being known for heterogeneity in intrinsic radio-sensitivity, attributable to tumour hypoxia and or tumour cell repopulation during treatment including dose of RT required for tumour cell ablation, loco-regional control rates are still low. One of the most important biological factors related to the outcome of RT in squamous-cell carcinoma is the tumour stem cells proliferation during treatment [3]. It is well known that the prolonged over all treatment time (OTT) would result in loss of tumour control by $0.6 \%$ per day, [4-6] and a substantial number of clinical reports show that reduction in overall treatment time might improve loco-regional control [7-9].

A shorter treatment time can be obtained by delivering higher dose per fraction, but this will result in disproportionate the incidences of late complications $[10,11]$. Alternatively Accelerated fractionation is if the 


\section{Original Research Article}

weekly number of fractions is increased without increasing the dose per fraction. This was studied by Danish Head and Neck Cancer Group (DAHANCA) 6 \& 7 trial which compared the same total dose of radiotherapy given to patients with HNSCC either conventionally (five fractions per week) or accelerated (six fractions per week using conventional technique [7].

The accelerated schedule enabled delivery of 66 Gy in 33 fractions, $\underline{8}$ days earlier than the conventional schedule, with an overall treatment benefit of around $15 \%$ more than the conventional schedule and an with manageable complications rate Thus, decrease in OTT can result in better tumour control, with the existing resources, provided the total dose is not reduced.

However this benefit associated with Accelerated fractionation by conventional 2D technique was masked due to associated higher normal tissue toxicities compromising the therapeutic gain. 12 However the benefit of AF using IMRT, is not so far evaluated which is the current standard of care in $\mathrm{H} / \mathrm{N}$ cancers.

The purpose of this study was to determine the feasibility and effectiveness of Accelerated fractionation using IMRT by assessing compliance of patients and the loco regional response comparing with concurrent chemoradiation.

\section{Materials and Methods}

In this prospective, non randomized, feasibility study, after obtaining ethical committee approval, 20 Patients with histologically proven invasive SCC of Oropharynx and Hypopharynx of Stage III to IVA, with performance status of WHO-0-2, with no history of prior RT or Surgery, deemed suitable for radical radiotherapy with curative intent were selected. Patients were staged according to TNM classification $7^{\text {th }}$ edition after clinical, radiological and endoscopic evaluation (Table 1). All patients underwent orodental assessment including dental prophylaxis.

Patients were immobilized with thermoplastic mask in supine position. Computed tomography (CT) images indexed every $3 \mathrm{~mm}$ were obtained, ranging

from vertex to $5 \mathrm{~cm}$ inferior to the clavicular heads.

Primary and nodal target volumes along with critical stucutres were delineated as per RTOG and Danish Head and Neck Cancer Group (DAHANCA) contouring guidelines on a contrast enhanced CT superimposed plain images.
Treatment planning was performed using the inverse planning algorithm. IMRT plans were genarated using 7-9 fields with dMLC optimiszation and patients were treated with altered fractionation scheme with six fractions per week, from Monday to Saturday, with sixth fraction delivered on Saturday. Thus reducing the overall treatment timewithout reduction in the total dose.

The treatment prescription and dose specifications were in accordence with guidelines of ICRU 50 and 62.

Gross Tumor Volume (GTV) - includes measurable and demonstable Primary (GTVp) and Nodal (GTVn) disease.

Clinical Target Volume 1 (CTV1) - includes $5 \mathrm{~mm}$ margin to $\operatorname{GTV}(\mathrm{p})$ and $\operatorname{GTN}(\mathrm{n})$, edited at bone, air cavities and fascia with no radiological evidence of invasion.

Planning target volume 1 (PTV1) - 5mm margin for CTV1. PTV1 to recieve 70Gy in 35 Fr.

Clinical Target Volume 2 (CTV2) - Includes CTV $1+$ entire nodal region.

Planning target volume 2 (PTV2) - 5mm margin for CTV 2 - PTV2 recieves 63Gy in 35 Fr.

Clinical Target Volume 3 (CTV 3) - Includes Low risk adjecent neck nodal region.

Planning target volume 3 (PTV3) - 5mm margin to CTV3. PTV3 to receive $56 \mathrm{~Gy}$ in $35 \mathrm{Fr}$.

All patients received concurrent chemothearpy with Cisplatin at a weekly dosage of $40 \mathrm{mg} / \mathrm{m} 2$

Treatment plan analysis- Dose-volume histograms (DVHs) of the PTVs and the critical normal structures were analyzed accordingly. For PTVs, we evaluated the volume covered by $95 \%$ of the prescribed dose (V95\%), Maximum point dose (D-max), Dose minimum (D$\min )$, Mean dose (D-mean).

The aim was to achieve $95 \%$ of the PTV to receive $95 \%$ of the prescribed dose and no more than $1 \%$ of the PTV to receive $>107 \%$ of the prescribed dose. For the critical organs with functional subunits organised in series such as brainstem, spinal cord, Mandible, D-max was evaluated. For critical organs with functional subunits organised in parallel such as cthe parotidsand cochlea, the D-Mean was evaluated. A QA program included a pre-treatment dosimetric check of all IMRT fields, using electronic portal imaging device (EPID). 


\section{Original Research Article}

Treatment Execution- All patients were given 6 fractions of radiation from Monday to Saturday and long with coucurrent Cisplatin at $40 \mathrm{mg} / \mathrm{m}^{2} /$ week. Treatment postion and adequecy of PTV margins were verified by pre-treatment EPID imaging on first 3 consecutive days of treatment and weekly, thereafter in order to calculate systematic and random error.

Response and Toxicity assessment- Response and Toxicity were assessed weekly. Tumour Response was assessed according to RECIST crieteria. Acute mucosal and skin toxicity was assessed and scored as per the RTOG Acute Radiation Morbidity Scoring system.

Chemotherapy induced renal and hematological toxicities were assessed as per the Common Toxicity Criteria for Adverse Events (CTCAE).
Follow-up- First follow-up was done at 4 weeks and subsequent follow-up at 3 months interval. During follow up, primary tumour and the nodal response were assessed separately along with radiological and endsocpic mapping. Acute mucosal and skin toxicity were assessed and scored respectively.

Statistical Methods- Descriptive and inferential statistical analysis has been carried out in the present study. Results on continuous measurements are presented on Mean SD (Min-Max) and results on categorical measurements are presented in Number (\%).

Significance is assessed at 5\% level of significance. Student $\mathrm{t}$ test (two tailed, dependent) has been used to find the significance of study parameters on continuous scale.

\section{Results}

In this study, the median age of the patients was 54 years ranging from 40 to 65 years. 17 were male and 3 were female. $16(80 \%)$ patients gave history of tobbacco and alcohol addiction. 14 (70\%) patients had Hypopharyngeal and $6(30 \%)$ had Oropharyngeal malignancy.

The T stage and $\mathrm{N}$ stage of the cohart is as per the table-2. Histologically, 12 (60\%) patients had well differentiated SCC, $7(30 \%)$ were moderaratley differrentiated and $1(10 \%)$ poorly differentiated. $19(95 \%)$ of patients received 70 Gy of radiation dose along with 4 cycles of concurrent Cisplatin. The Over all Treatment time (OTT) was 45 days in 18 (90\%) patinets.

The most common acute toxicity was mucositis, which was grade II and grade III in $6(30 \%)$ and $14(70 \%)$ of patients, respectively. Mucositis negatively impacted swallowing ability and causing mean weight loss of $8.3 \%$ and 5 (25\%) patients developed sever degrees requiring naso-gastric tube support.

Grade I, II dermatitis toxicity was observed in $14(70 \%)$ and 6(30\%) of patients, respectively. None had G-III or IV skin reactions. 5(25\%) patients had Grade II and 1 (5\%) patient developed Grade III Leucopenia. 4 (25\%) of patients required G- CSF support after 4 cycles of chemotherapy.

None of the patients developed Renal toxicity. None of the patients had hemoptysis, dyspnea, or stridor nor required tracheostomy. $5(25 \%)$ patients, grade 2 and $1(2 \%)$ grade 3 developed leucopenia after 4 cycles of chemotherapy. 5 $(25 \%)$ patients required tube feeding and or IV fluids for nutritional support.

Response Rates- Overall, complete response was seen in $80 \%(16 / 20)$ of the patients, partial response was seen in $20 \%$ $(4 / 20)$ of the patients.

Tumor Response Based on Different Variables- Complete response was observed 100\% in well deifferntiated, $66 \%$ in moderately differentiated and none in poorly differatiated carcinomas.

$17(85 \%)$ of oropharyngeal and $13(65 \%)$ of hypoparyngeal cancers showed complete response. $100 \%$ of T2 and T3 and T4b tumors and $80 \%$ of T4a tumors showed complete response.

In nodal disease $100 \%$ complete response among patients with $\mathrm{N} 1$ and $\mathrm{N} 2 \mathrm{a}$ lesions, while $91 \%$ in $\mathrm{N} 2 \mathrm{~b}$ and none in N3 disease.

TNM stage group wise the complete response rates were $100 \%$ in stage III, $92 \%$ in stage IVA, none in stage IVB. 


\section{Patient Characteristics}

Table-1

\begin{tabular}{|l|c|c|}
\hline Age in Years & No. & Percentage \\
$41-50$ & 5 & $25 \%$ \\
$51-60$ & 8 & $40 \%$ \\
$61-70$ & 7 & $35 \%$ \\
\hline Sex & 17 & $85 \%$ \\
Male & 3 & $15 \%$ \\
Female & & \\
\hline Habits & & \\
Smoking & 05 & $25 \%$ \\
No & 15 & $75 \%$ \\
Yes & & \\
Alcohol & 4 & $20 \%$ \\
No & 16 & $80 \%$ \\
Yes & & $95 \%$ \\
Pan Chewing & 19 & $5 \%$ \\
No & 1 & $90 \%$ \\
Yes & 18 & $10 \%$ \\
Betel Nut & 2 & \\
No & & \\
Yes & & \\
\hline
\end{tabular}

Tumor Response Based On Different Variables

Table-2: Correlation of study variables with overall response.

\begin{tabular}{|c|c|c|c|}
\hline \multirow{2}{*}{ Variables } & \multirow{2}{*}{$\begin{array}{c}\text { Total number of } \\
\text { patients }\end{array}$} & \multicolumn{2}{|c|}{ Overall Response } \\
\hline & & Complete response & Partial Response \\
\hline \multicolumn{4}{|l|}{ Site } \\
\hline$\square$ Hypopharynx & 14 & 12 & 2 \\
\hline$\square$ Oropharynx & 6 & 4 & 2 \\
\hline \multicolumn{4}{|l|}{ Clinical Stage } \\
\hline$\square$ III & 3 & 3 & 0 \\
\hline$\square$ IVA & 14 & 13 & 1 \\
\hline$\square$ IVB & 3 & 0 & 3 \\
\hline \multicolumn{4}{|l|}{ Tumor stage } \\
\hline$\square \mathrm{T} 2$ & 2 & 2 & 0 \\
\hline$\square \mathrm{T} 3$ & 11 & 11 & 0 \\
\hline$\square \mathrm{T} 4 \mathrm{a}$ & 5 & 4 & 1 \\
\hline$\square \mathrm{T} 4 \mathrm{~b}$ & 1 & 1 & 0 \\
\hline \multicolumn{4}{|l|}{ Nodal stage } \\
\hline$\square \mathrm{N} 0$ & 2 & 2 & 0 \\
\hline$\square \mathrm{N} 1$ & 3 & 3 & 0 \\
\hline$\square \mathrm{N} 2 \mathrm{a}$ & 1 & 1 & 0 \\
\hline$\square \mathrm{N} 2 \mathrm{~b}$ & 11 & 10 & 1 \\
\hline$\square \mathrm{N} 3$ & 3 & 0 & 3 \\
\hline \multicolumn{4}{|l|}{ Histology } \\
\hline$\square \mathrm{WD}$ & 12 & 12 & 0 \\
\hline$\square \mathrm{MD}$ & 6 & 4 & \\
\hline$\square \mathrm{PD}$ & 2 & 0 & 2 \\
\hline
\end{tabular}




\section{Discussion}

The design and choice of an accelerated protocol was ba sed on results of the DAHANCA 7 trail [22] where Cisplatin was used concurrently with RT, as a single agent or in combination with 5-FU or Mitomycin-C) with stanadard dose schedule of $100 \mathrm{mg} / \mathrm{m}^{2}$ bolus on days 1, 22 and 43 of RT. Randomised clinical trials comprisng so called non-standard schedules of platinum based CRT against RT alone [13,14,15] have treated equivalent numbers of patients as those that have compared bolus CDDP CRT against RT alone $[16,17,18]$.

It is clear that schedules that deliver drug in smaller doses on a more frequent basis are also quite effective in improving outcome.A common thread with respect to chemotherapy delivery in all of the sucessful RT / concurent single agent cisplatin schedules, both "standard" and otherwise is the delivery of a minimum cumulstive dose of $200 \mathrm{mg} / \mathrm{m} 2$ during the couse of irradiation. Hence Cisplatin of weekly $40 \mathrm{mg} / \mathrm{m} 2$ was used in this study. In this study $80 \%(16 / 20)$ of patients completed the intended treatment protocol of chemoradiation in less than 45 days. The rate of compliance was comparable to study by Staar et $\mathrm{al}^{19}$ which reported $90 \%$.

The significant toxicity in our study was mucositis. 70\% $(14 / 20)$ of the patients had grade III mucositis and 30\% $(6 / 20)$ had grade II mucositis. No patients had grade IV mucositis. This incidence grade 3 or more mucositis is less $(70 \%$ vs $80-85 \%)$ as compared to DAHANCA- $7^{20}$ and other studies with similar schedules $[21,22,19]$ and where hyper fractionation was used [13], its reported as upto to $95 \%$. All the cases with mucositis responded to conservative management. Mucositis appeared during the second week of treatment as hyperemia of the mucous membrane. Grade II mucositis was seen during the third week, while grade III mucositis was seen during the fifth week of treatment.

Mucositis compromised the ability to maintain nutrition with patients, on an average loss in baseline weight upto $8.3 \%$ which is comparable to study by Brizel et al which reported $10 \%$ mean weight loss. The proportion of patients who required and accepted a nasogastric tube was $20 \%(5 / 20)$, which was less compared to a multicentre randomized German trial [13] which mandated hospitalizing of all patients who were randomised to the chemotherapy arm (CDDP, 5-FU) and over half had a percutaneous gastrostomy for tube feeds prior to starting treatment.
$70 \%(14 / 20)$ of the patients had grade I skin reaction, $30 \%(6 / 20)$ grade II skin reaction. $25 \%(5 / 20)$ of the patients had grade II hematological toxicity and 5\% $(1 / 20)$ of the patients had grade III hematological toxicity in comparison with study by Dobrowsky and Naude $^{22}$ that reported $18 \%$ of grade $3-4$. None of the patients in our study had renal toxicity.

IMRT in head and neck cancer has proved better longterm preservation of salivary flow and better localregional control [23] in comparisons with conventional radiation techniques. Chao et al [24] reported that using IMRT for Stage III and IV oropharyngeal cancers, after a median follow-up of 33 months, the 4-year estimate of loco-regional control was $87 \%$ and disease-free survival was $81 \%$. With conventional radiation techniques, upto $95 \%$ of patients experience Grade 3 or higher mucositis after radiation therapy. The treatment in our study was well tolerated, with Grade 3 mucositis seen in $70 \%$ of patients.

Our study consisted of mostly advanced-stage study population, All the 20 patients $(100 \%)$, received concurrent chemotherapy. Both meta-analyses and randomized trials have established the role of concurrent chemotherapy in improving outcomes in head-and- neck cancers [25]. The recent update from Denis et al [18] has shown an improvement in overall survival and Loco regional control at 5 years using combined modality therapy for advanced-stage Oropharyngeal cancers. It follows that the common use of concurrent chemotherapy in our study is likely a contributing factor to the observed rates of initial tumor response and acute toxicities.

When we analyzed by $\mathrm{T}$ size and $\mathrm{N}$ stage, our study produced good response rates. It was significant even for advanced stages like $\mathrm{T} 4 \mathrm{a}$ and $\mathrm{T} 4 \mathrm{~b}$ tumors. The DAHANCA-7 reported that the whole benefit of acceleration came from improved T-site control, which further improved with chemotherapy.

Withers et al and Bentzen and Thames showed that a dose of 0.48 Gy per day was recovered by tumour during fractionated radiotherapy of HNSCC.

This was the reason why in our study in which overall treatment time was reduced by 1 week, produced higher response than conventional fractionation. By reducing overall treatment time by 1 week the 'dose recovery factor' of 3.3 was avoided. 


\section{Original Research Article}

Finally, all stages (except N3 nodes) showed improved response with accelerated radiotherapy using IMRT technique. The addition of chemotherapy has an added advantage. Patients with partial response of neck nodes underwent salvage neck dissection and are disease free till date. Long term follow-up is needed to look at the parameters like late toxicity, Loco-regional control, disease free survival and overall survival.

\section{Conclusion}

Accelerated fractionation in the form of 6 fractions a week using IMRT along with concurrent chemotherapy is a feasible in the treament of locally advanced head and neck cancer with good compliance. The locoregional response rates and toxicity profile were acceptable and were similar when compared with DHANCA 7 study.

Funding: Nil, Conflict of interest: None Permission of IRB: Yes

\section{References}

1. Ferlay J1, Shin HR, Bray F, Forman D, Mathers C, Parkin DM Estimates of worldwide burden of cancer in 2008: GLOBOCAN 2008. Int J Cancer. 2010 Dec 15; 127 (12):2893-917

2. National Cancer Registry Programme. Consolidated Report of the Population Based cancer Registries. 2001-2004. Indian Council of Medical Research. New Delhi. 2001.

\section{WHO Cancer Report 2008.}

4. National Comprehensive Cancer Network. Practice Guidelines: head and Neck cancer, version 1.2009. htpp/www.nccn.org/physician-gls/PDF/head-and-neckpdf.

5. Withers HR, Taylor JM, Machiejewski B. The hazarad of accelerated tumor clonogen repopulation during radiotherapy. Acta Oncol.1998;27(2):131-146

6. Fowler JF, Lindstrom MJ. Loss of local control with prolongation in radiotherapy. Int $\mathrm{J}$ Radiat Oncol Biol Phys. 1992;23(2):457-67

7. Soren M. Bentzen, and Howard D. Thames: Clinical evidence for tumor clonogen regeneration: interprettations of the data. Radiother Oncol 1991; 22: 161-166.

8. Steel GG. Basic Clinical Radiobiology. 3rd Edition. Hodder Arnold Pulishers; 2002.
9. Hall EJ, Giaccia AJ. Radiobiology for the Radiologist, 6thedition. LippincottWilliams and Wilkins Publishers; 2006.

10. Strandquist M: A study of the cumulative effect of fractionated X-ray treatment based on the experience mined at the Radium Hemmant with the treatment of 280 cases of carcinoma of the skin and lip. Acta Radiol 1944; 55[suppl]:1-300.

11. Orton CG, Ellis F. A simplification in the use of the NSD concept in practical radiotherapy. $\mathrm{Br} \mathrm{J}$ Radiol $1973 ; 46: 529-537$.

12. Overgaard J, Hansen HS, Specht L, Overgaard M, Grai C, Andersen E et al. Five compared with six fractions per week of conventional radiotherapy of squamous cell car cinoma of the head and neck: DAHANCA 6 \& 7 randomised controlled trial. Lancet 2003; 362: 933-940.

13. Brizel DM, Albers ME, Fisher SR, Scher RL, Richtsmeier WJ, Hars V et al. Hyperfractionated irradiation with or without concurrent chemotherapy for locally advanced head and neck cancer. N Engl J Med. 1998; 338(25):1798-1804 .

14. Jeremic B, Shibamoto Y, Milicic B, Nikolic N, Dagovic A, Aleksandrovic J et al. Hyper fractionated radiation therapy with or without concurrent low-dose daily cisplatin in locally advanced squamous cell carcinoma of the head and neck: a prospective randomized trial. J Clin Oncol. 2000 Apr, 18 (7): 1458-64.

15. Wendt TG, Grabenbauer GG, Rodel CM, Thiel HG, Aydin $\mathrm{H}$, Rohloff $\mathrm{R}$ et al. Simultaneous radiochemotherapy versus radiotherapy alone in advanced head and neck cancer: a randomized multicenter study.J Clin Oncol 1998; 16 (4):1318-1324.

16. Adelstein DJ, Li Y, Adams GL, Wagner H, Kish JA, Ensley JF et al. An intergroup Phase III comparison of standard radiation therapy and two schedules of concurrent chemoradiotherapy in patients with unresectable squamous cell head and neck cancer. J. Clin Oncol 2003; 21(1):92-98.

17. Forastiere AA, Goepfert H, Maor M, Pajak TF, Weber R, Morrison W et al.Concurrent chemotherapy and radiotherapy for organ preservation in advanced laryngeal cancer. N Engl J Med 2003 Nov 27; 349 (22): 2091-8. 
Original Research Article

18. Denis F, Garaud P, Bardet E, Alfonsi M, Sire C, Germain $\mathrm{T}$ et al. Final results of the 94-01 French Head and Neck Oncology and Radiotherapy Group randomized trial comparing radiotherapy alone with concomitant radiochemotherapy in advanced-stage oropharynx carcinoma. J. Clin. Oncol 2004 Jan 1; 22 (1): 69-76.

19. Staar S, Rudat V, Stuetzer H, Dietz A, Volling P, Schroeder $\mathbf{M}$ et al. Intensified hyperfractionated accelerated radiotherapy limits the additional benefit of simultaneous chemotherapy: Results of a multicentric randomized German trial in advanced head-and-neck cancer. Int J Radiat Oncol Biol Phys 2001 Aug 1; 50(5): 1161-71.

20. Bourhis J, Overgaard J, Audry H, Ang KK, Saunders $\mathrm{M}$, Bernier $\mathrm{J}$ et al. Hyperfractionated or accelerated radiotherapy in head and neck cancer: a metaanalysis. The Lancet 2006 Sep 2; 368 (9538): 843-54.

21. Budach V, Stuschke M, Budach W, Baumann W, Geismar D, Grabenbauer G et al. Hyperfractionated accelerated chemoradiation with concurrent fluorouracil mitomycin is more effective than dose-escalated hyperfractionated accelerated radiation therapy alone in locally advanced head and neck cancer: final results of the radiotherapy cooperative clinical trials group of the German Cancer Society 95-06 prospective randomized trial. J Clin Oncol 2005 Feb 20;.23(6):1125-35.

22. Dobrowsky W and Naude J. Continuous hyperfractionated accelerated radiotherapy with/ without mitomycin $\mathrm{C}$ in head and neck cancers. Radiother Oncol 2000 Nov; 57(2): 119-124.

23. Chao KS, Majhail N, Huang CJ, et al. Intensitymodulatedradiation therapy reduces late salivary toxicity without compromising tumor control in patients with oropharyngeal carcinoma: A comparison with conventional techniques. Radiother Oncol 2001 Dec;61 (3): $275-80$.

24. Chao KS, Ozyigit G, Blanco AI, et al. Intensitymodulatedradiation therapy for oropharyngeal carcinoma: Impact of tumor volume. Int J Radiat Oncol Biol Phys 2004 May 1;59(1):43-50.

25. Pignon JP, Maitre AL, Maillard E, Bourhis J. Metaanalysis of chemotherapy in head and neck cancer (MACH-NC): An update on 93 randomised trials and 17,346 patients. Radiother Oncology 2009 Jul 92(1): 4-14

\section{How to cite this article?}

Manjula M.V, Y.S. Pawar, Ashok S, Karthikeyan K. Altered Fractionation Intensity Modulated Radiotherapy with concurrent chemotherapy in head and neck cancer : a feseability study. Int J Med Res Rev 2018; 6 (08): 503-509. doi: 10.17511/ijmrr.2018.i08.16. 